\title{
Um Estudo Exploratório Da Gestão De Pessoas Na Integração E Disseminação Da Governança Corporativa
}

\author{
An Exploratory Study Of Personnel Management In The Integration \\ And Dissemination Of Corporate Governance
}

\author{
Daniel Oliveira ${ }^{1}$, Mauricio Pedro da Silva², Tabata Alana Lima³ ${ }^{3}$ Mônica Maria \\ Martins de Souza ${ }^{4}$
}

\begin{abstract}
1.Daniel Oliveira. Dr. em química. Diretor do NUPE - Núcleo de Pesquisa Eniac. Atua na direção administrativa da Faculdade de Tecnologia Eniac - FAPI E-mail: daniel.oliveira@eniac.com.br.

2.Mauricio Pedro da Silva é metrando em Governança Corporativa na FMU 2015, Prof. da Universidade Paulista - UNIP e da Faculdade de Tecnologia Eniac - FAPI e Orientador de Iniciação Científica. Pesquisador do NUPE - Núcleo de Pesquisa Eniac. Atua no mercado da Educação, de Recursos Humanos e Governança Corporativa. E-mail: <pr.mauriciopedro@gmail.com>

3;Tábata Alana Lima é graduada no Curso de Administração da Faculdade de Tecnologia Eniac - FAPI em Guarulhos de 2015, é atuante no mercado de trabalho de Recursos Humanos guarulhense SP.

4. Monica Maria Martins de Souza - Dra em Comunicação e Semiótica PUCSP. (2005), Mestre em Adm de empresas, Mackenzie SP. (1999). Éspecialista em Adm. de RH pela UNA. União de Negócios Adm. de BH, MG. (1995), e especialista em Tecnologia Educacional pela UNINOVE SP. (2000), é Psicóloga graduada Newton Paiva de BH/ MG. (1991). Atualmente é Profa convidada pela Pós-graduação do Mackenzie. Desde 2006 é avaliadora INEP. Profa. Dra, pesquisadora da Faculdade ENIAC, coordena grupos de pesquisa e iniciação científica e organiza seminários anuais desde 2009. É Profa. Dra. pesquisadora, coordenadora de Cursos e da Revista Acadêmica Augusto Guzzo das Faculdades Integradas Campos Salles - FICS desde agosto de 2010. Prestadora de serviços Administrativos da Euroatlantica Ghesa Brasil Ltda.
\end{abstract}

\section{Resumo}

Um estudo exploratório da gestão de pessoas na integração e disseminação da governança corporativa é a pesquisa exploratória realizada no cenário organizacional, proposto pela idealização de novas formas eficazes de gestão. O modelo de governança corporativa surgiu com o objetivo de conciliar interesses corporativos baseados em princípios de transparência, equidade, prestação de contas e responsabilidade. Demonstra a estrutura de poder das organizações, a sua forma de direção e estabelecimento das suas relações. Embora muitas organizações adotem o modelo como modismo baseado em um check list puramente normativo, a prática da governança corporativa não se resume a isso. Ela busca a solução das questões corporativas por meio da implementação de uma série de dispositivos que possibilitem aos investidores acompanhar as atividades das instituições. Permite que os stakeholders - investidores e pessoas envolvidas nos processos trabalharem com o máximo de transparência. $O$ estudo analisa a evolução e disseminação da governança corporativa com o objetivo de demonstrar os fatores influenciadores da organização. As responsabilidades dos administradores, a importância das áreas de controle, incluindo gestão de riscos e compliance. A pesquisa exploratória a partir da investigação bibliográfica procurou identificar como as práticas de governança corporativa influenciam diretamente na organização. Observou se os benefícios dessa iniciativa agregam valor à empresa e beneficiam os seus interessados mantendo a competitividade e transparência da empresa no mercado.

Palavras chave: Governança corporativa. Gestão das relações humanas. Criação de valor agregado. 


\begin{abstract}
An exploratory study of personnel management in the integration and dissemination of corporate governance is the exploratory research conducted in the organizational scenario, proposed by the creation of new effective ways of management. The corporate governance model emerged with the aim of reconciling corporate interests based on the principles of transparency, fairness, accountability and responsibility. Demonstrates the power structure of organizations, their form of direction and establishment of their relations. Although many organizations adopt the model as a fad based on a purely normative checklist, the practice of corporate governance is not just about that. She seeks the solution of corporate issues by implementing a series of devices that allow investors to track the activities of the institutions. Allows stakeholders - investors, and individuals involved in work, with the maximum of transparency. The study analyses the evolution and dissemination of corporate governance with the aim of showing the factors influencing the organization. The responsibilities of the directors, the importance of the control areas, including risk management and compliance. Exploratory research from the bibliographical research sought to identify how the corporate governance practices directly influence in the organization. Noted whether the benefits of this initiative add value to the company and enjoy their interested maintaining the competitiveness and transparency of company on the market.
\end{abstract}

Keywords: corporate governance. Management of buman relationships. Creation of benefit.

\section{Introdução}

O objetivo geral da pesquisa é compreender o modelo de governança corporativa no cenário organizacional como uma nova forma de gestão, verificar a sua possibilidade e eficácia e a sua capacidade de conciliar interesses corporativos baseados em princípios de transparência, equidade, prestação de contas e responsabilidade. O objetivo especifico é analisar a teoria da governança corporativa e destacar os aspectos humanos mais relevantes para o desenvolvimento da organização, demostrar os impactos da liderança positiva. Estudar os aspectos da gestão de pessoas, relatar as interferências culturais na governança corporativa, mostrar como a gestão influencia no crescimento da organização e posicionam a visão de liderança nesta.

A justificativa é fazer um levantamento da importância da teoria da governança corporativa voltada para as práticas de recursos humanos. Demonstrar que esta prática tem uma estrutura de poder nas organizações, e que a sua forma de direção e estabelecimento nas relações corporativas possui eficácia de acordo com o modelo adotado, não apenas como modismo 
baseado em um check list puramente normativo, e sim, muito mais que isso.

Para que as hipóteses possam ser confirmadas ou negadas por estudos posteriores as pesquisas exploratórias sobre a governança corporativa busca a solução das questões corporativas por meio da implementação de dispositivos que possibilitam aos stakeholders investidores e pessoas envolvidas nos processos, acompanharem as atividades das instituições com o máximo de transparência. Suas práticas influenciam diretamente uma organização, agregando valor, beneficiando os seus interessados e mantendo a sua competitividade e no mercado.

A metodologia utilizada na investigação se dará por meio da pesquisa exploratória e bibliográfica para analisar a evolução e disseminação da governança corporativa, os fatores influenciadores da organização, as responsabilidades dos administradores, a importância das áreas de controle, incluindo gestão de riscos. A pesquisa classificada como exploratório, de cunho essencialmente bibliográfico analisa os principais impactos da prática de governança corporativa. O trabalho de natureza exploratória envolve levantamento bibliográfico, entrevistas com pessoas envolvidas com as experiências práticas e o problema pesquisado estimulam a compreensão.

O referencial teórico aborda autores nacionais e internacionais no estudo exploratório considerado por Gil (2005:43) como "métodos e técnicas da pesquisa social que proporcionam uma visão geral de um fato aproximativo”. Os conceitos sobre Governança e cidadania empresarial são tratados por Alves (2001), os fundamentos, desenvolvimento e tendências são apontados por Andrade e Rossetti (2011). Os controles internos como um instrumento de governança corporativa são analisados por Bergamini (2005). Brum (2010) alinha o pensamento das pessoas às estratégias empresais. Brito (2003) pensa a controladoria de risco e o retorno em instituições financeiras. Calame (2001) discute o mercado da governança e a questão do Estado no coração do futuro. A lei de sociedade anônima n. 6.404, de 15 de dezembro de 1976, e as modificações das Leis n. 9.457, de 5 de maio de 1997 , e n. 10.303, de 31 de outubro de 2001 são comentadas por Carvalhosa (2003). A Gestão por competências é explicada por Dutra (2001). Hilb (2009) esclarece a nova governança corporativa como ferramenta bem-sucedida para conselho de administração. Oliveira (2006) diz que a gestão baseada neste modelo tem o poder de aperfeiçoar a estrutura e descreve a abordagem como facilitadora da consolidação de um diferencial competitivo dentro das empresas. A gestão de pessoas na integração e disseminação da governança corporativa cria valor e impacta na cultura organizacional, pois o diferencial das pessoas se adequam às empresas. 
1 Governança Corporativa Liderança E Cultura

Atualmente o tema vem sendo muito estudado e comentado por diversos tipos de profissionais, que focam no estudo do diferencial, que é a busca por transparência nos negócios. A governança passou a ser uma capacidade humana, onde a sociedade passou adotar sistemas de representação, de instituições e processos para elas mesmas se gerirem, em um movimento voluntário. Acabou virando o tema principal para alta gestão, atualmente, trata-se de um assunto importante para os executivos e colaboradores. Historicamente, governança corporativa sempre esteve focada na perspectiva de diretores e gerentes, que tradicionalmente tinham a incumbência de buscar maximizar a riqueza dos proprietários ou acionistas das empresas. As políticas sociais da empresa apresentam uma forte influência, variando em intensidade nos aspectos de confiança, satisfação no trabalho, capacidade de rede e comunicação e trabalho em grupo.

Do ponto de vista interno, a qualidade da governança pode contribuir para o sucesso ou fracasso empresarial, ocasionando diversos prejuízos. Do ponto de vista externo, a governança corporativa se situa no topo das atenções dos acionistas de todo o mundo, o que pode resultar em um acesso mais fácil ou mais difícil ao capital. Ademais, como as empresas estão naturalmente inseridas na comunidade, a forma como são governadas pode gerar impactos substanciais sobre terceiros, incluindo clientes, fornecedores, parceiros de negócios e sociedade em geral.

O estilo de liderança é um fator que se modifica de acordo com o posicionamento cultural do líder, tanto positiva quanto negativa. Essa capacidade de influência pode ser definida, como as ações ou exemplos que, direta ou indiretamente, estimulam mudanças no comportamento ou atitude de outra pessoa ou outro grupo. Os valores são muito relevantes para o ambiente institucional informal da sociedade, e podem ser adulterados dependendo de onde a empresa está sediada. As empresas ainda necessitam de grande evolução para o efetivo avanço dos mecanismos de governança no Brasil, pois os valores culturais muitas vezes são corrompidos. Independente da cultura da empresa, espera-se que as pessoas tomem as melhores decisões possíveis para o negócio. Isso inclui o cumprimento de normas e utilização do bom senso. O conflito de interesses e o viés cognitivo são tópicos muito relevantes quando se trata de governança corporativa, esses aspectos normalmente giram em torno do que se espera de profissionais envolvidos com a empresa. Dependendo do tipo de profissional, suas escolhas podem não ser adequadas para o que se espera dele.

O estudo realizado trata de aspectos da organização que como a ética, transparência e equidade, em primeira instância dependem da ação humana na empresa. Tatume e Berlin (2007) relatam que na governança a parte da 
gestão de pessoas, não pode ser ignorada, a ponto de estudos apresentados pela literatura abordarem as relações entre liderança, estilo dos tomadores de decisão, justiça organizacional com a criação de modelos que descrevem esta interação. Este estudo tem o objetivo de analisar a teoria de governança corporativa buscando destacar quais são os aspectos humanos que tem sido tratado pela produção científica nesta área.

A governança traz possibilidades de criar condições que evitem problemas antes que eles ocorrem, ou de tentar minimizá-los caso tenha ocorrido, além de promover padrões de comportamento universais, beneficiarão gerações futuras.

Whittington (2002) discorre que o conhecimento superior é o recurso mais valioso, não estando facilmente disponível em bancos de dados gerenciais. A chave para esse conhecimento está nas pessoas, bem como nas rotinas, na cultura e nas equipes que integram a organização. É preciso olhar o conhecimento como um recurso gerencial. A pretensão desse trabalho de contextos acadêmicos é apresentar argumentos que sustem a implantação da governança corporativa na gestão de pessoas pode melhorar o ambiente corporativo e proporcionar crescimento.

O papel do líder é criar valor de forma sistemática para o negócio. Uma empresa que decide adotar tais práticas passa a oferecer garantias de que os gestores exercem corretamente o seu papel liderando bem a equipe, levando a empresa rumo ao sucesso. Os níveis de governança ajudam os investidores a diferenciar as empresas que então alinhadas com as práticas mais modernas e transparentes. As vantagens são muitas, mas a principal é o respeito, credibilidade para a empresa.

A missão principal do líder no sistema de governança é fazer com que a organização tenha sucesso de forma sustentável. Para isso, todos colaboradores devem praticar hábitos da governança positiva. Alcançar níveis respeitáveis de sobrevivência e perenidade qualquer que seja o porte ou origem da empresa.

\section{Governança Corporativa}

A palavra, certamente francesa, nos vem, nesses últimos anos, por intermédio do inglês. Foi nas instituições de Bretton Wood - Banco Mundial, Fundo Monetário Internacional - que a expressão ganhou força. O conjunto dos poderes legislativo, executivo e judiciário. A administração, o governo, o parlamento, os tribunais, as coletividades locais, a administração do Estado, a Comissão Europeia, o sistema das Nações Unidas, são fatores marcantes em sua evolução, porém não serão muito mencionados nessa pesquisa. O conceito de governança corporativa na conjuntura mundial impõe dias de escassez de recursos a quase todos os mercados ao tempo em que imputa desafios cada vez mais limítrofes à exaustão levando as empresas a redefinirem suas políticas e posturas, como única forma de atuarem de maneira viável, coordenada e com horizontes factíveis. 
A governança surgiu para trazer facilidade e transparência ao mundo corporativo. Andrade (2011) relata que a expressão governança corporativa foi empregada pela primeira vez em 1991 por Robert Monks, nos Estados Unidos. Dando sequência a várias pesquisas, Oliveira (2006:12) já escrevia que "Pode-se afirmar que a governança corporativa teve suas origens em um tripé e se consolidou em um foco básico". tripé mencionado é firmado pelo fundo LENS, pelo relatório Cadbury e pelos princípios da OCDE, é o filtro básico do processo que corresponde à lei Sarbanes - Oxley. O fundo de investimento LENS, constituído por Robert Monks em 1992, efetivou um novo modelo de gestão para consolidar melhores resultados e maior valor para as empresas. Souza (2005) interpreta que este instrumento surgiu na economia anglo-saxônica como objetivo de aprimorar as relações entre as companhias e o mercado investidor. Este tripé pode ser observado na Figura 1.

Figura 1 - Tripé da governança corporativa

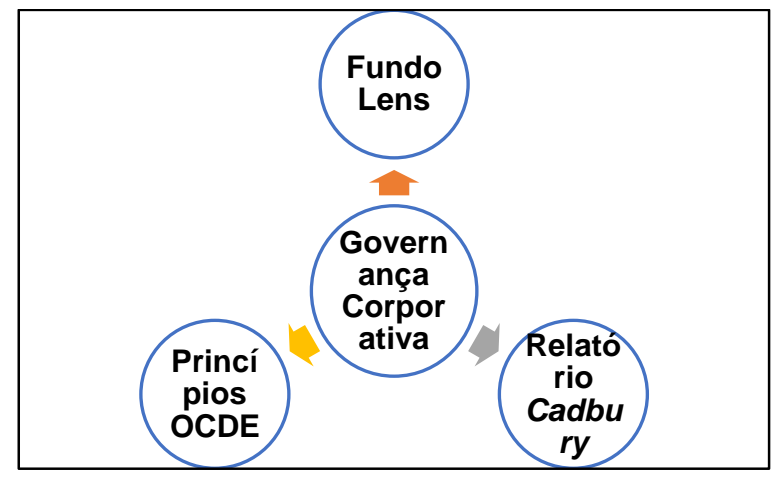

Fonte: Oliveira (2006, p.12).
Para Rossetti (2012), esse tripé é a formação e princípio da evolução do mundo corporativo. E com o passar do tempo o movimento foi se expandindo para os países europeus e hoje representa uma tendência em nível de mercado internacional. Lodi (2000) relata que a introdução da governança corporativa nas altas esferas de negócios se deu a partir do envolvimento de grandes líderes mundiais da iniciativa privada. E ao longo das três últimas décadas, a governança vem ganhando destaque exponencial nos âmbitos acadêmico e empresarial. $\mathrm{O}$ conceito desenvolvido por Lodi (2000) define governança corporativa como o sistema de relacionamento entre os acionistas, os auditores independentes, os executivos da empresa e os conselheiros de administração. Já Pierre (2001:21) a descreve como "A governança é a capacidade das sociedades humanas para se dotarem de sistemas de representação, de instituição e processos, de corpos sociais, para elas mesmas se gerirem, em um movimento voluntário”. A governança corporativa diz respeito ao controle dos recursos das empresas. Em qualquer situação em que o poder de decisão é transferido ou compartilhado, surge, em maior ou menor grau, uma assimetria informacional.

O Instituto Brasileiro de Governança Corporativa - IBGC (2015) define como um sistema pelo qual as organizações são dirigidas, monitoradas e incentivadas, envolvendo os relacionamentos entre proprietários, conselho de administração, diretoria e órgãos de controles. 
Com visão em outras linhas de estudo, Tirole (2001) afirma que governança corporativa é a defesa dos interesses dos acionistas; e uma boa estrutura de governança é aquela que seleciona os mais hábeis gerentes e os tornam responsáveis pelos investidores. $O$ termo abriga muitos estudos sobre controle da administração, ou sobre temas estritamente financeiros. Autores contemporâneos como Steinberg e Silveira vêm adicionando outras dimensões importantes à questão da governança.

Para Steinberg (2003:17) “[...]Governança é ainda algo meramente ligado à adequação a normas do mercado aberto de ações, direitos de minoritários, relatórios financeiros, regulamentos jurídicos e coisas assim". Ele amplia o conceito de governança, baseando-se na ideia de que é um engano imaginar que a prática da governança implica quase somente acatar regulamentos. Governança tem tudo a ver também com qualidade da atitude e escala de valores no mais puro sentido humano. Daí alguns consideram que a boa governança depende de alinhar o pensamento entre acionistas, controladores - stakeholders.

Esse pensamento enfatizando que "O tema pode ser definido como o conjunto de mecanismos que visam fazer com que as decisões corporativas sejam sempre tomadas com a finalidade de maximizar a perspectiva de geração de valor de longo prazo para o negócio". Neste contexto, Shleifer e Vishny (1997:737) afirmam que: "Governança corporativa lida com fornecedores e recursos que garantem retorno sobre seu investimento". Os administradores e controladores das companhias avaliam o processo através do conselho de Rappaport (1998:1):

\footnotetext{
Avaliar a empresa com o intuito de gerenciá-la com base na evolução do seu valor é preocupação atual de praticamente todos os principais executivos, fazendo com que nos próximos anos a criação de valor para o acionista provavelmente se torne o padrão global para remuneração do desempenho do negócio.
}

Um conceito de governança corporativa é, conjunto de princípios e práticas que procuram reduzir os conflitos de interesse entre os diferentes agentes da companhia com o objetivo de reduzir o custo de capital, aumentar o montante da entidade e o retorno aos acionistas. Em síntese, leva a melhores decisões, por meio de um processo decisório mais estruturado e embasado independente do ramo de atuação.

\subsection{Princípios Globais da Boa Governança}

O primeiro código das práticas de governança corporativa - o Cadbury Report - foi definido em 1992 na Inglaterra. Em 1995 foi editado o primeiro livro sobre o tema - "Corporate governasse", de R. Monks e N. Minow. A iniciativa do organismo multilateral para difusão dos princípios da governança para evidenciar seus efeitos positivos sobre o crescimento econômico das nações concluída em 1999, com a edição dos "Principles of corporate governance", da OCDE. 
Andrade (2011) discorre que as organizações com ou sem fins lucrativos possuem estrutura de poder e forma de direcionamento. Podem ser autocráticas, centralizadas, dependentes de pessoas especificas, formalizadas ou informais, podendo ser orientadas à atitudes éticas e cumprimento das regras, desenvolver cultura com foco em resultados financeiros, que se sobreponham aos meios ilícitos ou antiéticos, para obtê-los. A combinação de diferentes características de governança é indeterminável.

A questão central é que, diferente de um mero modismo gerencial ou de um tema técnico, as empresas podem ou não optar por implantar o modelo. A forma de governo pode ou não resultar de um processo reflexivo dos seus líderes. Silveira (2014:2) “ chama de governança corporativa um conjunto de práticas, de negócios alicerçadas sobre princípios comuns desenvolvidas a partir da década de 1990".

A discussão inicia a partir dos princípios que nortearam o movimento em prol da governança. A literatura internacional relata preceitos básicos da governança aplicáveis em qualquer tipo de organização. No Brasil, o IBGC elenca quatro em seu código de práticas: transparência, prestação de contas, equidade e responsabilidade corporativa. Dentro desses pilares o IBGC destaca a transparência e integridade das informações prestadas, a prestação de contas voluntaria e responsabilização pelas decisões tomadas. A avaliação de desempenho, remuneração justa e a meritocracia. Contrapesos independentes no processo decisório, a sustentabilidade e visão de longo prazo na condução do negócio. O respeito às formalidades, controles e supervisão independentes.

O tom e o comportamento ético das lideranças. A cooperação entre colaboradores e promoção do interesse coletivo da organização, A equidade e promoção da participação efetiva de todos os acionistas. A diversidade interna, o tratamento justo e a ausência de políticas e práticas discriminatórias. Com base nisso Silveira (2014) contrapõe que cada empresa possui suas peculiaridades em termos de estratégia, porte ou estrutura acionaria, em vista disso, para ele não há uma receita pronta de práticas a serem adotadas igualmente por todas as organizações. Cada objetivo se desdobra em questões chave que podem servir como apoio ou ponto de partida para as iniciativas de governança a serem empreendidas pelas empresas.

\subsection{Criação de Valor na Governança}

O objetivo maior dentro de qualquer organização é criar valor de forma sistemática para o negócio. Em outras palavras, fazer com que suas perspectivas de longo prazo sejam cada vez melhore ao longo do tempo. De uma visão geral é verificar se os investimentos em governança realmente contribuem para esse objetivo. Conforme elucida Silveira (2014:13) “Em primeiro lugar, é necessário harmonizar o 
conceito de valor", nada mais simples e nada mais complicado, o fator chave é destacar os conceitos de valor que a empresa pensa em instituir e a partir disso, implementar. Para Guerra (2014:76), atualmente presidente do IBGC:

"A criação de valor é tecida a partir de um ambiente de confiança e de uma perspectiva de longo prazo que leva em consideração o ambiente e a sociedade. Quando confio, não preciso descontar a incerteza no preço. Isso se aplica a um investidor assim como a um profissional que aposta o seu maior capital, seu tempo e seu talento, atrelando seu destino ao de uma empresa".

Steinberg (2003:18) menciona que "Governança tem tudo a ver com qualidade da atitude e escala de valores no mais puro sentido humano". Distintos estudos foram realizados a fim de demonstrar que os benefícios de se adotar as boas práticas e criar valores, poderiam ser mensuráveis e tangíveis para organizações e para a sociedade. Dentre os vários tópicos, buscaram investigar como características específicas de governança de uma companhia afetam sua rentabilidade, volatilidade das ações, valor das empresas e outros resultados. De vários fatores cruciais investigados os valores foram o que apontaram maior índice de persuasão. Os valores são condições para haver transparência e estímulos a atitudes éticas. Para ir mais adiante Villares (2002), presidente do IBGC no período de 2001/2003, defende a tese de que "Governança e ética andam juntas - uma organização".
Analisando esses estudos, pode-se dizer que a falta da boa governança pode destruir o valor das empresas, de mercados, de países e de pessoas. E a falta de valor pode causar o fracasso da governança e consequentemente o da empresa. Apoiando essa teoria Rossetti e Andrade (2011:328) dizem que "A governança é, assim, um relevante valor corporativo e social. Mas, por si só, ela não cria valor”.

A criação de valor ocorre quando se está organizacionalmente bem posicionados e gerenciados. Nesse caso, as práticas de governança corporativa permitirão uma gestão maximizando a criação de valor para todos os envolvidos. Em um estudo sobre a criação de valor e a disseminação da governança, Hilb (2009:31) menciona que "as práticas de governança corporativa são influenciadas pela característica do mercado".

Não é uma tarefa muito fácil conciliar os valores com os fatores internos e externos no aspecto de gestão de pessoas, mas, a prática pode levar a perfeição e crescimento. As empresas que nos últimos tempos vêm extraindo da governança corporativa os valores notavelmente diferenciados no mercado que adotam medidas de melhorias por princípios e não por obrigação, essas empresas fazem um caminho diferenciado em seu crescimento.

A partir das referências institucionais, seus administradores examinam com profundidade os regulamentos da governança da empresa, consideram as implicações de suas práticas e buscam constante aperfeiçoamento e 
como consequência criam valores institucionais imensuráveis.

\subsection{Os 8 Ps da Governança Corporativa}

$\mathrm{Na}$ construção e na operação de sistemas de governança geralmente estão presentes os 8 Os: propriedade, princípios, propósitos, papéis, poder, práticas, perenidade e pessoas. Rossetti (2011:143) em síntese conceitual afirma que “diversas dimensões da governança podem ser expostas por 8 Ps". Essa abordagem, conforme descreve Andrade (2012:144), pode ser compreendida a partir da figura 2.

Figura 2 - 8 Ps da Governança Corporativa

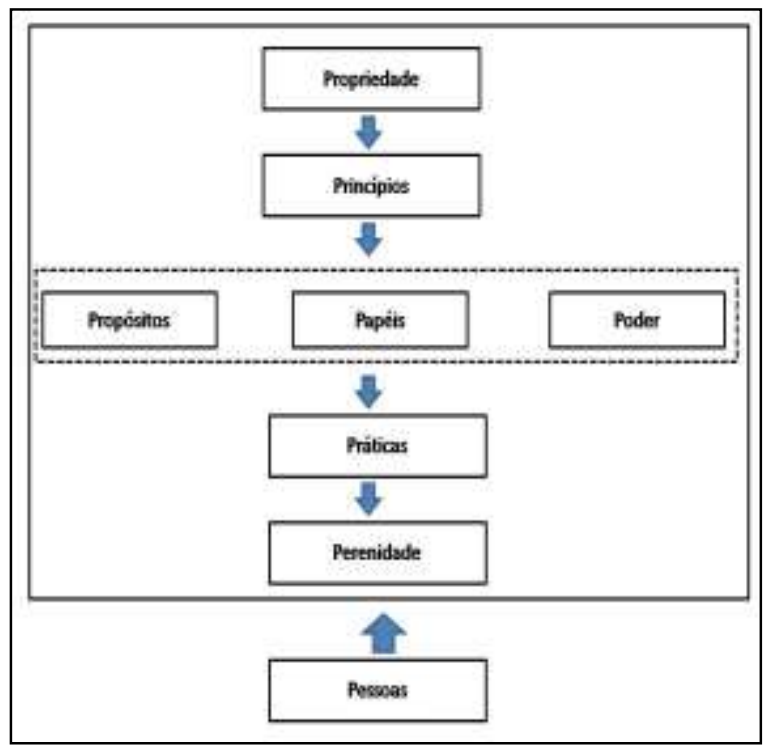

Fonte: Andrade e Rossetti (2011:144).

Pode-se definir a governança como um conjunto de princípios, propósitos, processos e práticas que rege o sistema de poder e os mecanismos de gestão das corporações. A tipologia da propriedade é um dos principais elementos definidores para a governança. Rossetti (2011:143) menciona que "Um dos principais atributos que diferenciam as razões de ser e as diretrizes da governança corporativa é a estrutura da propriedade nas companhias, bem como o regime legal de sua constituição". Rossetti e Andrade (2012:89) ressaltam que na sustentação de todo o sistema estão às pessoas condutoras do conjunto dos legados e dos objetivos que são vida e continuidade às operações corporativas. Os autores caracterizam os 8 Ps como sínteses conceituais da governança corporativa. São a partir das relações interpessoais íntegras, movidas por regras morais e harmoniosas, que se mitigam riscos de várias origens.

\section{O Despertar Da Governança}

A abordagem de Adolf A. Berle e Gardner C. Means, exposta em 1932 no clássico The modern corporation and private property, tratou de três aspectos cruciais da evolução do mundo corporativo: $\mathrm{O}$ afastamento entre a propriedade e o controle das grandes corporações, as mudanças no comando das companhias proprietários para gestores - as divergências de interesses entre eles, e a inadequação das concepções tradicionais sobre o controle das sociedades abertas e sobre o objetivo clássico sobre a maximização de lucros.

Andrade (2012:78) menciona que "O pioneirismo de Berle e Means fertilizou um novo campo de conhecimento, que nos últimos 20 
anos traduziu-se pela expressão governança corporativa". John Kenneth Galbraith, no clássico The new industrial state, de 1967, retomou, sem contrariá-las, mais em um tom mais critico e sarcástico, as novas realidades evidenciadas por Berle e Means, reenfatizando suas consequências e tendências. Andrade (2011) caracteriza esses acontecimentos como a evolução do mundo corporativo e enfatiza os aspectos mencionados como um poder por eles conquistado para chegada da governança corporativa. Uma teoria foi desenvolvida em 1971, a teoria de agência.

Segundo Okimura (2003), os primeiros estudos referentes à teoria da agência datam o início da década de 1970, através de artigos de Spence e Zeckhauser em 1971 e Ross em 1973. Suas análises estão centradas no processo de remuneração dos administradores das empresas, com o objetivo de tentar conjugar os interesses daqueles, com o interesse dos acionistas. As várias hipóteses de conflitos potenciais entre acionistas e gestores ou entre acionistas majoritários e minoritários têm sua origem. Mas é importante resumir agora as suas razões fundamentais, a partir de tratamento teórico convencional que foi desenvolvido nos últimos anos. Andrade (2011:82) menciona que: “A teoria já consagrada da governança corporativa denomina-os de conflitos de agências, associando-os a dois axiomas fundamentais, sintetizados por Klein e Jensen Meckling a inexistência do contrato completo e a inexistência do agente perfeito”.
A relação entre gestores e proprietários e entre controladores e minoritários dá-se o nome de relacionamento de agência. Jensen e Meckling (1976) citados por Silveira (2004:31) definem este relacionamento como "Um contrato no qual uma ou mais pessoas (o principal) contratam outra pessoa (o agente) para desempenhar alguma tarefa a seu favor, envolvendo a delegação de autoridade para tomada de decisão pelo agente". Nessa base de contesto, Lanzana (2004:40), apresenta quatro razões mais comuns para que haja conflitos de agência:

"A aversão ao esforço por parte do agente, o desvio de recursos por parte do agente para seu consumo pessoal, horizontes de tempo diferentes (o agente pode não estar tão preocupado com o efeito futuro de suas açôes, pois não planeja permanecer na companhia), diferentes níveis de aversão ao risco por parte do agente".

Para Andrade e Rossetti (2011:85):

$$
\begin{aligned}
& \text { "Os conflitos de agências no mundo dos negócios } \\
& \text { dificilmente serão evitados. E por duas razões: A } \\
& \text { primeira, sintetizada no axioma de Klein, segundo o } \\
& \text { qual não existe contrato perfeito. A segunda, } \\
& \text { sintetizada no axioma de Jensen - Meckling, que } \\
& \text { justifica a inexistência do agente perfeito". }
\end{aligned}
$$

Nesse sentido, os conflitos entre agentes e principais são derivados, em sua maioria, da expropriação realizada pelo controlador em detrimento dos demais acionistas. Dentro da governança corporativa centrou-se a tipologia do conflito de agência. Durante muito tempo, desde que Berle e Means, no inicio dos anos 30, 
chamaram a atenção para dispersão do capital das empresas, o problema crucial que hoje chamam de conflitos de agência centrou-se dentro da governança corporativa. Como registra Carvalho (2011), muito da literatura sobre governança corporativa baseia-se no princípio de que as empresas pertencem aos acionistas e que a sua administração deve ser feita em beneficio deles. O predomínio, por décadas, da visão descrita por Berle e Means (1976), segundo a qual as grandes empresas modernas possuem propriedade acionária dispersa, moldou o debate sobre a governança corporativa.

Conceitualmente, a governança corporativa surgiu para superar o conflito de agência, decorrente da separação entre a propriedade e a gestão empresarial. Nesta situação, o proprietário (acionista) delega a um agente especializado (executivo) o poder de decisão sobre sua propriedade. No entanto, os interesses do gestor nem sempre estarão alinhados com os do proprietário, resultando em um conflito de agência ou conflito agenteprincipal. Andrade (2011:87) menciona que "O grande problema de agência era visto como o conflito entre administradores e acionistas" os agentes executivos e agentes principais. $\mathrm{O}$ oportunismo consistiria de decisões dos administradores que não visassem à maximização do valor das ações. Dentro desse paradigma, boa governança empresarial significaria a adoção de mecanismos que forçassem os administradores (não acionistas) a proteger os interesses dos acionistas. Rossetti e Andrade (2011:89) relatam que:

$$
\begin{aligned}
& \text { "Esta, porém é apenas uma das categorias de conflito } \\
& \text { de agência, derivada de condições que prevalecem quando } \\
& \text { a estrutura de capitais é pulverizada e, por } \\
& \text { consequência, a propriedade e a gestão não são exercidas } \\
& \text { pelo mesmo agente. Outra categoria, que prevalece na } \\
& \text { maior parte dos países, é a da propriedade concentrada } \\
& \text { nas mãos de uns poucos acionistas majoritários, que } \\
& \text { pode levar à justa posição propriedade - gestão". }
\end{aligned}
$$

Neste caso a questão central da agência desloca-se do conflito de proprietários gestores para o conflito majoritário minoritário. Através de pesquisas Silveira (2002) fundamenta seu trabalho no conflito entre propriedade e controle das empresas. Segundo ele, a necessidade da governança corporativa de alinhar os interesses de gestores e acionistas é resultado do chamado problema de agências quando o administrador, que deveria sempre atuar no melhor interesse do proprietário, deixa de fazê-lo visando primeiro ao próprio interesse, na tentativa de melhorar sua utilidade pessoal.

Silveira (2002) discorre sobre isso dizendo que em economias menos desenvolvidas e com grande concentração de capital em mãos de poucos, o conflito de agências entre acionistas majoritários e minoritários se exacerba e contribui para deduzir as projeções de retornos financeiros dos analistas do mercado de capitais para alimentar o custo de capitais das empresas, reduzindo seu valor econômico e de mercado. Para minimizar 
e controlar os conflitos, dentro da governança foi criado os conselhos. Onde os investidores também uniram suas forças nas assembleias, elegendo um maior número de conselheiros.

Steinberg (2003:84) de certo relata "Nem sempre o executivo vai cumprir as vontades e os desejos dos donos ou acionistas. O conselho é um importante filtro entre os dois grupos". Os conselhos tornaram-se apaziguadores de conflitos em muitas organizações, dependendo do tipo de empresa podem-se encontrar dois tipos de conselhos, o administrativo e o familiar. Existem cerca de 6 tipos de conselhos estudados dentro da governança corporativa, porém somente esses dois serão abordados nessa pesquisa. $O$ conselho de administrativo no ambiente de governança corporativa, quando estruturado segundo os códigos de melhores práticas e esse conselho é o órgão guardião dos interesses dos proprietários. Para Rossetti e Andrade (2011:272) "Se trata de um órgão de caráter nuclear, dotado de poderes emanados da Assembléia Geral, em torno do qual gravitam os demais órgãos da administração”. Silveira (2010:258) caracteriza como “O conselho de administração é o elo entre os acionistas e a gestão diária das companhias". O órgão em si tem como função procurar maximizar o valor de longo prazo da empresa. Beiner, Schmid e Zimmerman (2004:24) possuem uma opinião bem enfática sobre o assunto, para os autores “ $\mathrm{A}$ governança começa e termina no conselho de administração”. O IBGC (2015) define como "Guardião das boas práticas de Governança, o
Conselho é responsável pela orientação geral, definição da estratégia e monitoramento dos planos de ação, além de se manifestar sobre o desenvolvimento da Governança Corporativa no País".

Conforme Carvalho (2002:19), o conselho de administração "Deve ser o órgão que manifesta a forma do relacionamento dos acionistas e o mercado financeiro e de capitais". Assim, a partir do entendimento das regras e da conciliação dos diversos interesses, o conselho de administração determina a posição da empresa frente aos seus credores e investidores. Oliveira (2011:89) caracteriza “A missão do conselho de administração é a definição de sua razão de ser”. E Lodi (2000:47) menciona que:

\begin{abstract}
"A missão do conselho de administração é proteger o patrimônio e maximizar o retorno do investimento do acionista, agregando valor ao empreendimento. $O$ conselho de administração deve zelar pela observância dos valores, crenças e propósitos dos acionistas nas atividades da empresa".
\end{abstract}

Oliveira (2006:04) contrapõe Lodi (2000:47) com relação ao "Conselho de Administração ser órgão deliberativo e estruturado com as finalidades básicas de proteger o patrimônio da empresa e maximizar o retorno dos investimentos dos acionistas". A deliberação corresponde a um processo de análise, debate e decisão a respeito de assuntos básicos de uma empresa ou negócio. Este aspecto proporciona uma disciplina administrativa, e estabelece uma personalidade 
de atuação, que seja adequada e aceita pelo mercado. Pode ser um diferencial competitivo para a empresa, segundo opinião de Oliveira (2006:05) "A adequada estrutura do conselho de administração deve facilitar a interação para com os valores e crenças da empresa, os aspectos éticos e a questão da responsabilidade social". Para Harvard Business Review (2001:10) “os conselhos de administração como um todo detectam os primeiros sinais de problemas e disparam o alarme". O conselho administrativo exerce funções diferenciadas dependendo da segmentação e estrutura acionaria da empresa, porém em todos os aspectos possui responsabilidades e poderes imensuráveis.

O conselho famíliar tornou-se apropriado para se desenvolver a gestão de conflitos gerados por empresas familiares envolvidos no direcionamento da empresa. O IBGC (2015) descreve como um fórum de dialogo e deliberações sobre expectativas e condutas de pais e filhos a primos e sobrinhos. Não importando o grau de parentesco, a atuação dos membros da companhia caracteriza um clã. A governança compreende diversos ambientes de tomadas de decisão, mas é o conselho familiar local, o legitimo para o gerenciamento do negócio prossiga respeitando a cultura afetiva existente no grupo.

O Conselho de Família deve existir como parte integrante da Governança Corporativa quando uma ou algumas famílias forem proprietárias da empresa. " $\mathrm{Na}$ realidade, esta é uma das práticas de governança recomendada" conforme Oliveira (2006:77). O autor menciona que o conselho familiar deve ter dois objetivos básicos: Consolidação do processo sucessório e Perpetuação da empresa familiar. Na esfera acadêmica, as pesquisas realizadas sobre os conselhos de família são inconclusivas e quase nunca são mencionadas. Embora funcionem adequadamente dão segurança aos membros das futuras gerações, abrem espaço para discutir problemas, emoções, dinheiro, educação e futuro; e podem ser um ponto de apoio decisivo para a continuidade da empresa familiar em situação de conflito".

Estes concelhos não são regidos pela lei da S.A. Não é necessariamente um órgão estatutário, mas sim uma instituição formal definida por meio de acordo de acionistas, com orçamentos específicos muitas vezes ligados a uma empresa familiar. Os membros do conselho são indicados em assembleias de acionistas ou famílias, quando representantes de cada grupo familiar irão representar os seus interesses neste conselho.

\section{O Fator Humano Na Governança}

Governança corporativa não é um tecnicismo que pode ser delegado para ser implantado por determinadas áreas. $\mathrm{Na}$ verdade, a boa governança depende do equacionamento de questões intrinsecamente humana nas organizações empresariais, algo que exige, acima de tudo, substancial investimento de tempo e envolvimento das principais lideranças. Além da 
Visão Tradicional a literatura tradicional transmitiu durante muito tempo a ideia de que a mera implantação de estrutura de incentivo remuneração variável, avaliação de desempenho dentre outros - e de controle seria suficiente para que as empresas se tornassem bem governadas. Silveira (2014:26) complementa que "Embora os mecanismos sejam elementos de um sistema de governança, a implantação de estruturas de incentivo e controle não é suficiente para assegurar empresas bem governadas". Na visão tradicional da governança, o cerne deriva da ideia limitada da cenoura e do chicote. Essa ideia permitiu que muitos líderes empresariais passassem a tratar o tema como um conjunto de check-lists a ser cumprido de maneira técnica, fria e desconectado do dia a dia da organização. $\mathrm{O}$ foco no fator humano, por sua vez, que permitirá alcançar o objetivo maior da governança. Criar um ambiente no qual as pessoas desejem voluntariamente tomar decisões no melhor interesse de longo prazo do negócio e cumprir regras".

Tricker (2000) sugere que a metamorfose da governança corporativa precisa acontecer. A prática atual se baseia no conceito legal do século XIX, inadequado ao ambiente global de negócios. A teoria não é capaz de explicar a maneira como as empresas modernas estão sendo governadas. $\mathrm{O}$ autor conclui que:

\footnotetext{
"É preciso uma maneira alternativa de se assegurar que o poder seja exercido, sobre todo tipo e forma de entidade corporativa e aliança estratégica ao redor do mundo, de tal maneira que se garanta tanto um efetivo desempenho
}

quanto uma apropriada responsabilidade e prestação de contas sociais" (TRICKER, 2000:295).

Silveira (2014:26) complementa dizendo “A governança corporativa foi reduzida a um conjunto de mecanismos de incentivo e de controle". Por contraste, Shleifer e Vishny (1997:737) sugere que a governança corporativa lida com "As formas pelas quais fornecedores de capital asseguram o retorno sobre os seus investimentos". Hilb (2009:19) descreve "Defino a nova governança corporativa como um sistema pelo qual empresas são estrategicamente dirigidas, de forma empreendedora e ética". Durante muito tempo a visão tradicional da governança focou exclusivamente em fatores financeiros, mas, com o passar do tempo e de sua evolução, fatores humanos passaram a ser considerados e mensurados na literatura. A Nova Governança conforme Hilb (2009) integra estruturas de pessoas e papéis, sem tirar o devido foco e estudo que cada um desses aspectos merece ao ser estudado. Para muitos autores o assunto que anteriormente era de interesse essencialmente de acadêmicos se tornou uma questão efervescente no âmbito mundial, tanto para pesquisadores como para praticantes. Porque então as pessoas não fazem o que deveriam fazer? Barbosa (2011:11) diz que: “As pessoas não fazem aquilo que deveriam fazer simplesmente porque não dão o primeiro passo. Elas pensam na jornada e anteveem todas as dificuldades, o esforço, o tempo necessário para fazer a coisa acontecer" e faz menção a fatores psicológicos que impedem 
as pessoas de desempenhar suas tarefas de maneira adequada.

A governança positiva começa pela compreensão dos três motivos centrais que levam as pessoas - em sua atuação como colaboradores, executivos, conselheiros ou acionistas - a, muitas vezes, não tomarem as melhores decisões passiveis para o negócio e a não cumprimento das regras. Silveira (2014) menciona que os três motivos são: limitações técnicas, conflito de interesses e o vieses cognitivo. Por conta desses três fatores muitas vezes processos que deveriam ser desenvolvidos dentro das empresas são fracassados. Steinberg (2003:84) afirma que:

"As pessoas criam as melhores e as piores práticas. Essa pequena frase [...] foi cunhada para sintetizar a ideia de que, por trás de todo procedimento jurídico e financeiro estão a vontade e o sentimento do ser humano - de que emana tudo o que é enaltecedor e tudo que é condenável”.

Fatores internos e externos podem influenciar na tomada de decisão na hora de desempenhar as funções dentro da empresa. Será abordada os três principais dentro da governança que geram conflito de interesses. A grande preocupação atualmente estudada dentro da governança corporativa é criar um conjunto eficiente de mecanismos, tanto de incentivos quanto de monitoramento, a fim de assegurar que o comportamento dos executivos esteja sempre alinhado com o interesse dos acionistas, ou vice e versa. Muitas vezes esses princípios aparentemente tão básicos, não são tão fáceis de serem empregados por conta do conflito de interesses. De acordo com a definição do IBGC (2015) o conflito de interesses ocorre quando alguém não é independente em relação á matéria em discussão e pode influenciar ou tomar decisões motivadas por interesses distintos daqueles da organização.

A expressão foi delimitada como uma situação na qual um profissional integrante de uma organização empresarial, tinha interesses contrários ao da empresa em uma decisão que devesse ser por ele tomada ou da qual ele pudesse de alguma forma participar do assunto a ser decidido. Para Silveira (2014:28) “O conflito de interesses é a questão central que motivou inicialmente debates sobre a governança corporativa". Basicamente, ele ocorre quando interesses secundários de uma pessoa envolvida em uma decisão podem divergir do interesse coletivo da empresa ao qual deve lealdade. $\mathrm{O}$ próprio tratado de Berle e Means (1932), considerado o marco inicial da governança corporativa, teve como objetivo analisar empiricamente a composição acionaria das grandes empresas e discutir os inevitáveis conflitos de interesse.

É importante destacar que o conflito existe independentemente da influencia efetiva do interesse secundário sobre a decisão final, o que tende a causar confusão sobre o tema. É uma situação comum, uma pessoa acusada de estar sobre conflito de interesses negar sua existência por não ter agido de forma impropria 
ou antiética. Silveira (2014, p.28) completa dizendo "Na verdade, o conflito de interesses é uma situação anterior à decisão, que pode existir mesmo que não ocorram atos impróprios decorrentes da atuação do indivíduo conflitado". Já de acordo com a Lei no 12.813/2013, conflito de interesses é a situação gerada pelo confronto entre interesses públicos e privada, que possa comprometer o interesse coletivo ou influenciar, de maneira imprópria, o desempenho da função. Ao analisar as informações mencionadas, podese concluir que o conflito de interesses pode influenciar o agente a não tomar a melhor decisão na execução de seu cargo pelos vieses cognitivos. A abordagem tradicional para governança corporativa se concentra quase que exclusivamente na criação de mecanismos a fim de alinhar os interesses dos gestores aos da organização. Silveira (2014, p.36) afirma que os "Vieses cognitivos são erros previsíveis e sistemáticos decorrentes de crenças e preferencias pessoais que levam as pessoas a tomarem decisões que fogem da racionalidade". Para Heavyrick (2013) o viés é utilizado para expressar o sentido de parcialidade, onde uma análise é feita de maneira tendenciosa, baseadas não em evidências, mas na percepção pura e simples que a pessoa tem de uma situação. Silveira (2014:34) discorre sobre o tema:

"Em outras palavras, parte-se do pressuposto que os executivos sabem quais são as melhores decisões de negócio a serem tomadas, porem precisam de um conjunto de mecanismos de incentivo (ex.: sistema de remuneração), e de controle (ex.: auditoria) para que não optem por outros cursos de ação em função de seus interesses particulares".

Mesmo que as situações, envolvendo conflito de interesses sejam resolvidas e que os executivos sejam altamente qualificados, a governança positiva possui outro potencial. A criação de um sistema de pesos e contrapesos diminui a chance de que decisões erradas sejam tomadas, devido aos chamados vieses cognitivos, aos quais todos estão sujeitos embora haja limitações técnicas. À medida que a complexidade organizacional aumenta, torna-se cada vez mais improvável que um único individuo detenha todos os conhecimentos para as decisões chave da empresa. A limitação técnica pode ser vista como o primeiro motivo central para que as pessoas dentro de uma organização tomem decisões ruins que podem ser prejudiciais ao bom direcionamento da organização. Esse é um problema que se torna critico, nas organizações familiares que estão sujeitas à elevada concentração de poder. Nesses casos, os mecanismos de governança, podem levar a melhores decisões empresariais.

\section{Elementos Centrais De Um Bom Modelo De Governança}

A compreensão das motivações e limitações humanas constitui o elemento central para a criação de um contexto organizacional que fomente a boa governança do dia a dia. $\mathrm{O}$ foco no fator humano por sua vez, deve ser complementado por um bom modelo de 
governança, isto é, por uma infraestrutura composta por órgãos, áreas e regras que proporcionem um sistema efetivo de pesos e contrapesos na organização.5.1 O Papel do Líder na Boa Governança A abordagem tradicional feita pelas empresas para a questão dos controles internos passou a levar em consideração os fatores psicológicos que podem aumentar a chance das pessoas descumprirem as políticas organizacionais. Silveira (2014:58) evidencia que:

\footnotetext{
"Os colaboradores e executivos terão interesses em cumprir as regras voluntariamente desde que acreditem que agindo desta forma estarão fazendo o melhor não apenas para a organização, como também para si mesmos e para a sociedade no longo prazo. As principais lideranças possuem o papel - chave neste processo, já que cabe ativar a consciência das pessoas neste sentido".
}

Apesar de parecer uma afirmação obvia para muitos, esse é um tema pouco abordado na governança corporativa. A visão tradicional sobre o tema, procura maximizar o resultado pessoal no seu dia a dia corporativo - em detrimento do resultado coletivo. Steinberg (2003:122) contrapõe que: “A boa governança corporativa demanda novas competências conceito que tem mais a ver com qualidade de atitude do que com capacidade de realização. Exige atributos que produzam sensação de respeito e levem a aquisição de credibilidade". Brum (2010:121) menciona que "Os líderes devem ser capazes de promover o direcionamento da informação, ter uma visão empresarial ao repassá-la". Sobre essa perspectiva Oliveira (2011:126) comenta que a:

\begin{abstract}
'Liderança é o processo em que uma pessoa é capaz, por suas características individuais, de entender as necessidades dos executivos e profissionais da empresa ou negócio, bem como exprimi-las de forma válida e eficiente, obtendo o engajamento e a participação de todos no desenvolvimento e implementação dos trabalhos necessários ao alcance das metas e objetivos estabelecidos".
\end{abstract}

Mais que um canal o líder é a empresa. Ele representa a empresa, especialmente para as pessoas da base. Quando a liderança não comunica os procedimentos ou normas da empresa o empregado acaba se contentando com o acesso informal. De acordo com Brum (2010:122) “É nesse momento que acontece a entropia da informação, quando, por falta de uma versão oficial, o empregado cria suas próprias verdades e as dissemina junto aos seus colegas de trabalho". Silveira (2014:65) aborda que "A consciência e o comportamento cooperativo, portanto, são forças importantes que levam as pessoas a cumprirem as regras voluntariamente, comportamentos que devem ser cultivados pelas lideranças interessadas na governança para valer". Cabe aos líderes criarem um contexto social mais propício à ativação da consciência das pessoas, deixando de concentrar exclusivamente em controles e incentivos. 
A Responsabilidades dos Administradores independente do porte da organização e de sua forma de constituição jurídica como capital aberto ou fechado, todos os membros, incluindo conselheiros, diretores e outros, estão sujeitos a determinados deveres gerais e fiduciários. Segundo Silveira (2014:88) "Em primeiro lugar, tendo em vista que seus cargos the oferecem um poder irrenunciável, todos estão sujeitos ao chamado poder - dever de agir”. Isso significa que esses membros denominados doravante de administradores têm o dever de agir em prol do interesse social quando as circunstâncias existirem podendo ser punidos em caso de passividade e opção pelo não exercício de poder.

O art. 153, da Lei 6.404/1976, traz expresso o dever de diligência do administrador, que deve agir com probidade na condução dos negócios da companhia, como se seu os fosse. Trata o art. 153, de um padrão que deve ser seguido pelo administrador no desempenho de suas funções, como o bonus pater famílias (CARVALHOSA, 2003:268). O administrador será responsabilizado, então, no caso de não observância da diligência necessária à condução dos negócios da companhia. Dar-se-á sua responsabilização no caso de agir com culpa, ou seja, com negligência, imprudência ou imperícia. A culpa poderá ser apurada quando agir culposamente ou se omitir, gerando a obrigação de indenizar companhia. Sobre o administrador recai, ainda, a responsabilidade por atos, que esteja na ilicitude ou ilegalidade, de seus subordinados, uma vez que, estes, devam ser supervisionados funcionalmente por aqueles.

Carvalhosa (2003:269) comenta que "A responsabilidade só será excluída se o administrador provar que lhe era ocultado pelo subordinado tais atos ilícitos". A finalidade das atribuições e o desvio de poder do administrador são os temas tratados no art. 154 da Lei 6.404/1976. É necessário observar que o administrador não se obriga pelo resultado alcançado pela companhia, mas somente pelo desempenho de suas funções. Assim, a obrigação a que se submete é de meio e, sendo desleal ou havendo desvio de poder, deve ser responsabilizado. $\mathrm{O}$ administrador deve vigiar sua conduta para não ocorrer desvio de poder, que nos dizeres de Carvalhosa (2003:274) "Caracteriza-se pelo desvirtuamento da finalidade da própria lei societária e do estatuto da companhia, embora preservados os elementos formais da respectiva regra".

Em observação à lei societária e ao estatuto, o administrador deve buscar os fins sociais, atentando para o interesse social em que o interesse da companhia é elevado acima dos seus interesses pessoais. Tudo isso considerando o bem comum e a função social da empresa. Silveira (2014:90) destaca que "Compreender os potenciais passivos legais aos quais está sujeito é um tema fundamental para qualquer administrador". A final de contas até que ponto suas decisões ou omissões podem levar a uma responsabilização do ponto de vista pessoa. 
Além das responsabilidades descritas nos parágrafos anteriores, os administradores podem ser responsabilizados nas esferas administrativas ou criminais. Como pode ser visto ser um administrador de empresas, particularmente conselheiro ou diretor estatutário, há muitos riscos envolvidos. A Gestão de Riscos envolve o velho adágio que diz: "sem riscos, não há resultados". Como qualquer decisão com consequências futuras envolve incertezas, todas as empresas estão continuamente expostas aos mais diferentes tipos de riscos. Para Bergamini (2006:01) na definição clássica de risco é “A possibilidade de ocorrência de um evento adverso para uma determinada situação esperada”. O economista Frank Knight em sua dissertação de doutorado (completada em 1916, em Cornell, e publicada em livro, em 1921, sob o título "Risk, uncertainty and profit" foi pioneiro em observar que risco e incerteza são manifestações da mesma força fundamental - a aleatoriedade - à qual estão associadas situações de escolha. Seu trabalho diferenciava a incerteza mensurável, ou o risco propriamente dito, da incerteza não mensurável. Essa diferenciação concedeu grande utilidade na tomada de decisões sob condições de incerteza.

A gestão de riscos é a aplicação de estratégias para evitar ou reduzir os custos gerados pelos riscos. Com propriedade Brito (2003:15) menciona que “A gestão do risco é o processo por meio do qual as diversas exposições ao risco são identificadas, mensuradas e controladas". Ou seja, a gestão é fundamental para que empresa compreenda os riscos, dimensionando-os e adequando-os aos seus objetivos relacionados ao retorno pretendido. Sendo que a não identificação, mensuração e controle desses riscos acabam colocando em dúvida a sua própria continuidade. Essa forma de pensamento leva as organizações a melhorar a forma que identificam, avaliam e tratam os seus riscos. O IBGC (2015) destaca a gestão como um:

$$
\begin{aligned}
& \text { "Processo desenhado para identificar e responder a } \\
& \text { eventos que possam afetar os objetivos estratégicos da } \\
& \text { organização Suas diretrizes devem ser estabelecidas pelo } \\
& \text { concelho de administração e as ações decorrentes devem } \\
& \text { ser implementadas pelos gestores, com o objetivo de } \\
& \text { prover, com razoável segurança a realização das metas } \\
& \text { da organização a partir de um adequado alinhamento } \\
& \text { da estratégia com seu apetite de riscos". }
\end{aligned}
$$

Para Araújo (2010), é importante no tratamento dos riscos que as ferramentas de gerenciamento ofereçam agilidade e precisão. $\mathrm{O}$ processo de gerenciamento de riscos deve estar suportado por ferramentas que possibilitem o estabelecimento de critérios para classificar a natureza do risco e a identificação de quais áreas da empresa ou que processos de negócios abrigam esses riscos. Além de reduzir as surpresas operacionais e os prejuízos, com a identificação de riscos transversais às organizações, transformando certos riscos em oportunidades. A gestão de risco integra soluções no âmbito das organizações com a finalidade de gerir os riscos inerentes aos 
negócios. A utilização de ferramentas de ponta na identificação e avaliação do risco adicionada a ferramentas de gerenciamento de processos de negócio que visam aperfeiçoar os resultados das organizações será o diferencial competitivo para a tomada ágil de decisão considerando os controles internos.

Os riscos operacionais decorrem da realização diária ou não de operações de todos os tipos, estando associado direta ou indiretamente ás deficiências nos controles internos. De acordo com o Committee of Sponsoring Organizations of the Treadway Commission COSO (2013:5), principal referência sobre o tema, controles internos são "Processos, implementados pelo conselho de administração, diretoria e outras lideranças, desenhados a fim de proporcionar segurança razoável em relação ao alcance dos objetivos operacionais, e de compliance da empresa”. O IBGC (2015) principal executivo é responsável pela criação de sistemas de controle internos que organizem e monitorem um fluxo de informações corretas, reais e completas para a sociedade, como as de natureza financeira, operacional, de obediência às leis e outras que apresentem fatores de risco importantes. Assim, o American Institute of Certified Public Accountants (AICPA), citado por Crepaldi (2007:269), define "O controle interno compreende o plano de organização e todos os métodos e medidas adotados na empresa para salvaguardar seus ativos, verificar a exatidão e fidedignidade dos dados contábeis, desenvolver a eficiência nas operações e estimular o seguimento das políticas administrativas prescritas".

O controle interno auxilia as entidades a alcançar os seus objetivos, e a sustentar e melhorar o seu desempenho. Sobre o assunto Silveira (2014:105) esboça sua opinião comentando "As áreas de controle são um elemento central a fim de evitar surpresas desagradáveis e ajudar a promover a boa governança". Isso é particularmente importante na medida em que a empresa cresce e adquire maior complexidade organizacional. Apesar do relativo consenso geral em relação a esta afirmação, muitas empresas continuam a possuir áreas de controle deficientes. Esse paradoxo acontece devido a dois motivos principais mencionados por Silveira (2014): o custo envolvido e a percepção de sucesso do negócio. COSO (2015:11):

\footnotetext{
"O controle interno não é um processo em série, mas sim um processo dinâmico e integrado. A estrutura aplicase a todas as entidades de grande, médio e pequeno porte, com e sem fins lucrativos, além de órgãos governamentais. Cada organização, entretanto, pode escolher implementar o controle interno de forma diferente. Por exemplo, o sistema de controle interno de uma entidade de pequeno porte pode ser menos formal e estruturado, mas ainda ser eficaz".
}

Um sistema de controle interno eficaz exige mais do que a estrita observância a políticas e procedimentos, exige o uso de julgamento. A administração e a estrutura de governança se utiliza de julgamento para determinar que o nível de controle seja suficiente. $\mathrm{O}$ administrador e 
outros membros devem usar o julgamento todos os dias para selecionar, desenvolver e distribuir os controles por toda a entidade. Indo mais a fundo, pode-se tomar como base de estudo o mencionado por COSO (2013:11):

\footnotetext{
"A Estrutura requer que haja julgamento no desenho, implementação e condução do controle interno e na avaliação de sua eficácia. O uso de julgamento, dentro das limitações estabelecidas pelas leis, regras, regulamentações e normas, aumenta a capacidade da administração de tomar melhores decisões sobre o controle interno, embora não possa assegurar que o resultado será perfeito".
}

O controle interno não é capaz de evitar julgamentos errôneos ou más decisões, ou ainda eventos externos que impeçam a organização de atingir suas metas operacionais. Em outras palavras, até mesmo um sistema eficaz de controle interno pode apresentar falhas. Com propriedade o economista Bergamini (2005:14) discorre que "Nesse processo, cabe ao Conselho de Administração a definição das diretrizes estratégicas e de algumas diretrizes específicas, geralmente ligadas à otimização do processo de supervisão". A diretoria executiva deve programar e implementar as ações diretas necessárias para o cumprimento dessas diretrizes. Com relação aos instrumentos e mecanismos de governança corporativa e ao ambiente de controle, devem ser avaliadas todas as decisões antes de implementá-las com Compliance. Expressão que tomou corpo nos últimos anos no mundo empresarial representa em sua essência "a conformidade da organização a normas externas e internas, tais como leis, regulamentações políticas corporativas" conforme Silveira (2014:109). As instituições financeiras foram compelidas a iniciar um ciclo de mudanças cada vez mais radicais, com reestruturações estratégicas, organizacionais e tecnológicas, para construir uma imagem forte da instituição financeira perante clientes e fornecedores. Nesse contexto, destaca-se a função de Compliance de grande importância na proteção e no aprimoramento do valor e da reputação corporativa.

$$
\mathrm{Na} \text { visão do BACEN (2007) "Ser }
$$
Compliance significa conhecer as normas da organização, seguir os procedimentos recomendados, agir em conformidade e sentir quando é fundamental a ética e a idoneidade em todas as nossas atitudes". De acordo com a FEBRABAN o Compliance, integra aos demais pilares da Governança Corporativa, chegando no momento em que essas transformações ocorrem simultaneamente, e sua implementação nas instituições financeiras brasileiras tem importância e missão que vão além do implícito na Resolução emitida pelo Conselho Monetário Nacional no artigo 2.554/98, inseridas em mudanças que visam alinhar seus processos, assegurar o cumprimento de normas e procedimentos e, principalmente, preservar sua imagem perante o mercado. $\mathrm{Na}$ concepção de Argenti citado por Manzi (2008:39): 


\begin{abstract}
'Para que a 'Função de Compliance' seja eficaž é necessário o comprometimento da alta administração e que esta faça parte da cultura organizacional, contando com o comprometimento de todos os funcionários. Todos são responsáveis por compliance. Um Programa de Compliance eficazpode não ser o suficiente para tornar uma empresa à prova de crises. Mas certamente aprimorará o sistema de controles internos e permitirá uma gestão de riscos mais eficiente".
\end{abstract}

O Comitê da Basileia refere-se à função Compliance e não a uma estrutura fixa como uma diretoria ou departamento, por causa das diferenças existentes em função da jurisdição, porte, tipo de instituição e natureza das atividades desenvolvidas. No Brasil a aprovação da lei n 12.846 em 2013, conhecida como lei anticorrupção, elevou de vez a importância da estruturação das atividades de ética e Compliance nas empresas como forma de reduzir passivos legais. Silveira (2014:112) em uma tentativa de melhor introdução ao tema destaca que "A chave para o sucesso, na verdade, é implantar uma cultura de confiança e integridade com o engajamento direto da alta gestão, notadamente do diretor presidente e demais lideranças". A responsabilidade pela tomada de decisões tomadas é dependente da cultura corporativa. A conformidade da empresa para com as regras precisa ser vista como responsável por cada área e não apenas da área de compliance, que deverá proporcionar orientação sobre o tema, centralizar informações e levar adiante a agenda.

As atividades de Compliance inserem-se em um contexto de gestão preventiva de riscos, de monitoramento e supervisão contínua sobre as práticas corporativas e operações cotidianas, como forma de garantir que a instituição respeite as boas práticas de governança. Silveira (2014:113) menciona que: “Apesar de constituir um grande desafio, a construção de um sistema eficaz de compliance deve ser vista como uma oportunidade da organização em assegurar um padrão de excelência operacional, diminuir o risco de problemas reputacionais, mitigar passivos legais e promover valores".

A missão da área de Compliance em uma Instituição está voltada a assegurar a existência de políticas e normas, pontos de controle nos processos para mitigar riscos, relatórios que visem melhorias nos controles internos e práticas saudáveis para a gestão de riscos operacionais. Tudo isso para garantir credibilidade frente a clientes, fornecedores, acionistas e colaboradores, de forma transparente, assegurar que a estrutura organizacional e os procedimentos internos estão em conformidade com os regulamentos externos e internos, além de permitir que a companhia mantenha suas finanças saudáveis, minimizando riscos de perdas.

\section{Considerações Finais}

A governança surgiu quebrando preconceitos acadêmicos e dando novas formas a administração das empresas. As deixando de forma mais nítida, clara e transparente em relação aos negócios e suas finanças. Na medida em que a governança corporativa passou a ser mais disseminada no mercado, muitas pessoas 
recém-expostas ao tema passaram a visualizá-lo apenas como um conjunto de práticas a serem implementadas de forma técnica, saltando a etapa fundamental de internalização de seus preceitos basilares. Muitas companhias aderiram técnicas de check-list, exigindo práticas como um atestado de qualidade em governança. É de opinião da autora que a governança corporativa não possui um modelo único, parecendo estar evoluindo rumo a um modelo caracterizado por um maior profissionalismo e transparência, embora não tão abrangente e completo conforme preconizado pelas boas práticas em vigor.

Com o passar do tempo, os princípios de governança foram convertidos em um número variável de práticas recomendadas versos modismo mal aplicado nas organizações. Tendo em vista, que cada empresa possui uma peculiaridade em termos de estratégia, porte, estilo de mercado etc., não há um roteiro ou receita de práticas a serem adotadas por cada empresa, apenas modelos e normas que podem ser desenvolvidas e evoluídas para a inclusão da governança corporativa. A diversidade dos agentes e dos interesses envolvidos no mundo corporativo é que dirão o rumo que a organização ira seguir, os diferentes modelos de gestão podem ser alinhados em uma única reta dentro da organização, reta essa chamada de progresso corporativo. Os motivos pelos quais atuais modelos de governança não contemplam as estratégias de gestão de pessoas estão tão relacionados com o modelo de liderança quanto à própria empresa. Durante muito tempo dentro da governança foi focado o modelo de remuneração por competência, não que essa não seja viável, por que é, mais as formas que até então estavam sendo empregadas muitas vezes ocasionavam conflitos que faziam com que a organização em si perdesse credibilidade e notoriedade perante o mercado.

A liderança desempenha um pape fundamental quando se trata de orientar e de certa forma influenciar os demais na tomada de decisão correta. O modelo de governança espera que o profissional envolvido dentro da organização seja honesto e transparente por que ele quer ser, por gostar de fazer parte da organização, por assim dizer o líder tem o papel de dar o exemplo positivo. Cabe aos líderes criarem um contexto social mais propício à ativação da consciência das pessoas, deixando de se concentrar exclusivamente em controles de incentivos, pois os fatores humanos são muito mais complexos, dependendo de questões muitas vezes psicológicas. É necessário perceber que na estrutura da boa governança que tenha como objetivo criar um contexto organizacional no qual as pessoas desejem de fato agir no melhor interesse ao longo do prazo da organização. Nessa nova abordagem os mecanismos de controle e incentivo da visão tradicional continuam a ser importante, porém não devem ser aceitos como suficiente para assegurar empresas bem governadas. Outro fator relevante que merece atenção dentro da boa governança é a implantação do compliance. 
Apesar de sua importância, ainda são raras as empresas não financeiras que contam com um programa estruturado, que complete ações de aculturamento e mecanismos de prevenção, detecção e solução de não conformidades. Há diversas formas de se aprimorar a conformidade da empresa aos regramentos impostos interna e externamente.

A boa governança exige transparência, harmonia com os melhores padrões éticos e conformidade com normas internas e externas. Ela garante a credibilidade perante o mercado e justifica os atuais investimentos na governança corporativa dentro das organizações. $\mathrm{O}$ cumprimento de normas é indispensável para relações de equidade entre a empresa e seus stakeholders, e para o comportamento responsável da empresa e de seus dirigentes. Através governança, busca-se ainda mitigar os interesses divergentes da alta gestão em relação aos interesses da empresa. O compliance pode ser considerado como um dos pilares da governança corporativa devido ao fortalecimento do respeito a normas e políticas, bem como a mitigação de riscos. A empresa em compliance preserva a sua imagem, o que reduz a possibilidade de danos à reputação. A empresa deve atribuir a cada colaborador a obrigação individual de respeitar as normas e contribuir para a preservação da corporação Compliance disseminado na estrutura organizacional: obrigação individual de cada colaborador em respeitar as normas e contribuir para a preservação da corporação.
Decisões tomadas com princípios da boa governança, representam uma abordagem nova de gestão com ênfase na responsabilidade de todos os envolvidos com a empresa. Diante de um novo paradigma para as ciências administrativas. A adoção do sistema de governança corporativa, claramente melhora a imagem da institucional da empresa no mercado, valorizando seu patrimônio, ou seja, sua marca. Diante do que foi exposto, pode-se dizer que essa forma de administração chegou para ficar, e se prevê que um novo horizonte de valores agregados se abrirá em seu destino. O tema da governança corporativa está associado aos aspectos comportamentais como cultura organizacional, ética dos funcionários, liderança, responsabilidade social, confiança. Gestão das pessoas com foco no treinamento, remuneração e seleção. Prevalece no aspecto comportamental, as questões de confiança e transparência, que são fatores essenciais para o estabelecimento de relações duradouras, retomada da credibilidade perante os investidores e melhoria do clima organizacional. Especialistas em recursos humanos têm pesquisado sobre estes assuntos, para encontrarem caminhos que levem as empresas a retomarem sua credibilidade ou melhorarem seu clima organizacional.

Esforços que unidos às boas práticas de governança corporativa, melhoram sua competitividade e atraem investidores. Por outro lado, as questões de remuneração do executivo, treinamento e seleção, referentes à gestão de pessoas aplicada à governança, contribui abordar 
o conflito de interesse associado a confiança, bem como o aspecto da transparência na retomada da credibilidade dos investidores. Ambos os aspectos, serão tratados nos próximos tópicos.

Pode-se concluir que a Governança Corporativa através da gestão, estratégia, visão e controle trazem vantagens, vendo possível notar a aceitação das práticas da governança corporativa e de seus princípios por todos os envolvidos na gestão empresarial e também no mercado como um todo. Outro fator é o estimulo dado aos investidores pelo fato de que as empresas que adotam os valores, princípios e se adequam as normas da gestão, tem por objetivo o seu próprio desenvolvimento, destaque no mercado e sua perenidade. A Governança corporativa é de vital importância para que as empresas possam passar maior credibilidade no mercado e alavancar seus investimentos através de novos futuros investidores, resultando na melhoria da macroeconomia do país. Diante das inúmeras formas que podem ser encarados o preceito relativo ao tema da governança corporativa expõe-se a seguir, algumas maneiras pelas quais pode ser abordado, não pretendendo é claro, esgotá-lo. Em pesquisas futuras pretendo: Concentrar o estudo na área de economia, analisando as relações de mercado de capitais, visando encontrar empresas que adotem as boas práticas de governança, perante os Stakeholders. Testar, através de modelos econométricos, se a adoção das práticas de governança tem efeitos na melhora da imagem e apreçamento dos papéis das empresas. Observar, por meio de modelos econométricos, se adoção dessas práticas tem efeitos na redução do custo de captação dos recursos, via mercado de capitais, por essas empresas.

\section{Referências Bibliograficas E Eletronicas}

ALVES, L. Governança e cidadania empresarial. RAE -Revista de Administração de Empresas, v. 41, n. 4, p. 78-86, 2001.

ANDRADE, Adriana, ROSSETTI, José Paschoal. Governança corporativa: fundamentos, desenvolvimento e tendências, 5.ed.São Paulo: Atlas, 2011;

Banco Central do Brasil, Auditoria interna e compliance na visão do BACEN: perspectiva e responsabilidade. $8^{\circ}$. Congresso FEBRABAN de Auditoria Interna e Compliance, 2007

BERGAMINI, Sebastião Junior. Controles Internos como um instrumento de governança corporativa. Revista do BNDES, Rio de Janeiro, V. 12, N. 24, P. 149-188, dez. 2005.

BRUM, Analisa de Medeiros. Endomarketing de A a Z: como alinhar o pensamento das pessoas à estratégia da empresa. São Paulo: Integrare Editora, 2010.

BRITO, Osias Santana de. Controladoria de risco - retorno em instituições financeiras. São Paulo: Saraiva 2003

CALAME, Pierre. A questão do Estado no coração do futuro: o mercado da governança; tradução de Ephraim Ferreira Alves. Petrópolis, 
RJ: Vozes; Montevidéu, Uruguai: Ediciones Trilce, 2001.

CARVALHOSA, Modesto. Comentários à lei de sociedades anônimas: Lei n. 6.404, de 15 de dezembro de 1976, com as modificações das Leis n. 9.457, de 5 de maio de 1997, e n. 10.303, de 31 de outubro de 2001. São Paulo: Saraiva, 2003.

DUTRA, Joel Souza. Gestão por competências.

2. ed. São Paulo: Gente, 2001.

GIL, A.C. Métodos e técnicas de pesquisa social. São Paulo: Atlas, 1999.

\section{HARVARD BUSINESS REVIEW.}

Experiências de governança corporativa.

Tradução: Afonso Celso da Cunha Serra. Rio de Janeiro: Campus, 2001.

HEAVYRICK, Ricardo. Historia e caos: vieses cognitivos. Disponível em < http://historikaos.blogspot.com.br/2013/05/v ieses-cognitivos.html> Acesso em 11 maio 2015. HILB, Martin. A nova governança corporativa: ferramentas bem-sucedidas para conselho de administração; tradução e revisão técnica Luiz Fernando Turatti, Wesley Mendes Silva. São Paulo: Saint Paul Editora, 2009.

$\begin{array}{lc}\text { INSTITUTO } & \text { BRASILEIRO DE } \\ \text { GOVERNANÇA } & \text { CORPORATIVA. }\end{array}$

Governança corporativa e criação de valor. São Paulo: Saint Paul Editora, 2015.

Governança corporativa: origem.

Disponível

em

$<\underline{\text { http://www.ibgc.org.br/inter.php? }}$

$\underline{\mathrm{id}=18161 / \text { governanca-corporativa }}>$ Acesso em

12 mar.2015.
MACHADO FILHO, Cláudio Pinheiro. Responsabilidade social e governança: o debate e as implicações, governança e reputação. São Paulo: Pioneira Thomson Learning, 2006.

MANZI, Vanessa A. Compliance no Brasil Consolidação e perspectivas. São Paulo: Saint Paul, 2008.

OLIVEIRA, Djalma de Pinho Rebouças de. Governança corporativa na prática: integrando acionistas, conselho de administração e diretoria executiva na geração de resultados. São Paulo: Atlas, 2006.

PEREIRA, Carmen Silva, QUELHAS, Osvaldo Luís Gonçalves. Organização \& estratégia 2 (2005) 58-81 64. Disponível em http://www.latec.uff.br/bt/v2006/Volume $\% 2$ 02005/PDF/ BT004 2005.pdf. Acesso 25 fev. 2015.

RAPPAPORT, Alfred. Creating shareholder value: a guide for managers and investors. 2 . ed.New York: The Free Press, cap.1-3, 1998.205p.

ROMAGNOLE, Silvana. Conselho de Família uma ferramenta estratégica para famílias empresárias. Disponível em < http://www.silvanaromagnole.com.br/site/?p =compexp\&i=84> Acesso em 04 mar. 2015.

SILVEIRA, Alexandre Di Miceli da. Governança corporativa no Brasil e no mundo: teoria e prática. Rio de Janeiro: Elsevier, 2010. SHLEIFER, Andrei, VISHNY, Robert. A survey of corporate governance. Journal of Finance, v. 52, n. 2, p. 737-783, 1997. 
STEINBERG, Herbert. A dimensão humana da governança corporativa: pessoas criam as melhores e piores práticas. São Paulo: Editora Gente, 2003.

WHITTINGTON, Richard. O que é estratégia.

São Paulo: Pioneira Thomson Learning,2002. 